\title{
Enhanced anti-tumor immunity against breast cancer induced by whole tumor cell vaccines genetically modified expressing $\alpha$-Gal epitopes
}

\author{
DABING XUE ${ }^{1 *}$, YING LIANG $^{1 *}$, SILIANG DUAN ${ }^{*}$, JIAN HE $^{1}$, JING SU $^{1,2}$, JIANMENG ZHU $^{1}$, \\ NAN HU ${ }^{1}$, JIANMING LIU ${ }^{2}$, YONGXIANG ZHAO ${ }^{1}$ and XIAOLING LU ${ }^{1,3}$ \\ ${ }^{1}$ National Center for International Research of Biological Targeting Diagnosis and Therapy, \\ Guangxi Key Laboratory of Biological Targeting Diagnosis and Therapy Research, \\ Collaborative Innovation Center for Targeting Tumor Diagnosis and Therapy, \\ Guangxi Medical University, Nanning, Guangxi 530021; ${ }^{2}$ Department of Respiratoy Diseases, \\ The Third Hospital of Central South University, Changsha, Hunan 410013; \\ ${ }^{3}$ The Department of Immunology, Guangxi Medical University, Nanning, Guangxi 530021, P.R. China
}

Received March 9, 2016; Accepted June 27, 2016

DOI: $10.3892 /$ or.2016.5128

\begin{abstract}
Whole tumor cell vaccines have shown much promise, but demonstrated poor efficiency in phase III trials. In this study, we modified MDA-MB-231 tumor cells (MDA-MB-231 ${ }^{\mathrm{Gal}+}$ ) to express $\alpha-1,3$-galactosyltransferase $(\alpha-1$, 3-GT) protein, to potentially enhance antitumor effect of whole tumor cell vaccines. MDA-MB-231 tumor cell vaccines were transfected with a reconstructed lentiviral containing $\alpha-1,3-G T$ genes. Tumor growth, tumorigenesis and survival of Hu-NODSCID mice were observed when tumor-bearing mice were injected with tumor cell vaccines. Proliferation and apoptosis in MDA-MB-231 tumor xenografts were observed by immunohistochemistry. The levels of cytokine secretion in the serum of mice were tested by ELISA. CD8 ${ }^{+} \mathrm{T}$ cells infiltrating tumors were assessed by flow cytometry. MDA-MB-231 ${ }^{\mathrm{Gal}+}$ cells expressed active $\alpha-1,3-\mathrm{GT}$ and produced $\alpha-\mathrm{Gal}$ in vitro. MDA-MB-231 ${ }^{\mathrm{Gal}+}$ cell vaccines suppressed tumor growth and tumorigenesis in immunized Hu-NOD-SCID mice. Additionally, decrease of TGF- $\beta$, IL-10 and increase of INF- $\gamma$, IL-12 were observed in tumor cell vaccinated mice. Furthermore, the cell vaccines enhanced infiltration of cytotoxic $\mathrm{CD}^{+} \mathrm{T}$ cells in the tumor
\end{abstract}

Correspondence to: Professor Yongxiang Zhao or Professor Xiaoling Lu, National Center for International Research of Biological Targeting Diagnosis and Therapy, Guangxi Key Laboratory of Biological Targeting Diagnosis and Therapy Research, Collaborative Innovation Center for Targeting Tumor Diagnosis and Therapy, Guangxi Medical University, Nanning, Guangxi 530021, P.R. China

E-mail: yongxiang_zhao@126.com

E-mail: luwuliu@163.com

*Contributed equally

Key words: whole tumor cell vaccines, $\alpha-1,3-\mathrm{GT}$, antitumor microenvironment of immunized mice. The MDA-MB-231 $1^{\mathrm{Gal}+}$ cell vaccines modified $\alpha-1,3-$ GT genes improved the antitumor effect.

\section{Introduction}

Whole tumor cell vaccines have been investigated for a long time in clinical and basic studies (1-3). Whole tumor cell vaccines have obvious advantages in cancer immunotherapy (4). First of all, whole tumor cell vaccines offer a wide spectrum of tumor antigens (5) and unknown tumor associated antigen to elicit tumor-specific immunity (6). Second, whole tumor cell vaccines facilitate a high-efficiency antitumor response (7). Whole tumor cell vaccines were processed and presented all tumor antigen peptides to induce a robust polyclonal $\mathrm{T}$ cell immune response by $\mathrm{MHC}$ class I and class II of dendritic cells. The $\mathrm{CD}^{+}{ }^{+} \mathrm{Th}$ cells stimulated by whole tumor cell vaccines could also promote $\mathrm{CD} 8^{+} \mathrm{T}$ cells to generate a stronger antitumor effect and long-term memory (2). Numerous phase I and II clinical trials have shown that whole tumor cell vaccines had significant clinical benefits. However, phase III clinical trials of whole tumor cell vaccines usually fail to produce significant clinical effect (8-10). Many studies have shown that the lack of tumor antigen expression in cancer evolution and immunosuppression exploited by the tumor itself may be the main determinant of the limited efficiency $(11,12)$. Therefore, in order to improve the antitumor effect of whole tumor cell vaccines, exploiting other antitumor approach is required.

The $\alpha-\mathrm{Gal}$ is a carbohydrate epitope, which is generated in pigs and New World monkeys by the $\alpha$-1,3-galactosyltransferase $(\alpha-1,3-\mathrm{GT})(13-15) . \alpha-\mathrm{Gal}$ epitope does not exist in humans and old world monkeys because their $\alpha-1,3-$ GT genes have become silenced during biological evolution (16-18). As humans do not have $\alpha$-Gal epitopes, they produce a lot of anti- $\alpha-G a l$ antibody in response to stimulation of gastrointestinal bacteria (19-21). 
$\alpha$-Gal on cell surface could trigger rapid humoral immune response and strong cellular immune response. In addition, $\alpha$-Gal also promote T cell division and secretion of TNF- $\alpha$, and IFN- $\gamma(22,23)$. These results suggest $\alpha-\mathrm{Gal}$ is a potential adjuvant for cancer immunotherapy.

We modified genetically MDA-MB-231 cell vaccines by replication defective retroviral expressing $\alpha-1,3-\mathrm{GT}$ genes Our results demonstrated that the whole tumor cell vaccines expressing $\alpha$-Gal produced high efficient protection and antitumor immunity. In conclusion, our data showed that whole tumor cell vaccines expressing $\alpha$-Gal enhanced therapeutic antitumor effect.

\section{Materials and methods}

Cells and animals. The human breast cancer cell line MDA-MB-231 cells were purchased from American Type Culture Collection (ATCC, VA, USA). MDA-MB-231 cells were cultured in complete DMEM media (Gibco, CA, USA) with $10 \%$ fetal bovine serum (FBS) and $100 \mathrm{U} / \mathrm{ml}$ penicillin/ streptomycin. MDA-MB-231 ${ }^{\mathrm{Gal}+}$ cells expressing $\alpha-1,3-\mathrm{GT}$ and control cells were obtained by GenScript (Nanjing, China) and maintained in DMEM cultured with $10 \% \mathrm{FBS}, 100 \mathrm{U} / \mathrm{ml}$ penicillin/streptomycin and $0.35 \mu \mathrm{g} / \mathrm{ml}$ puromycin.

NOD.CB17-Prkdcscid/NcrCrlVr (NOD-scid) mice 3-4 weeks of age were obtained from Vital River Lab Animal Technology Co.(Beijing, China). They were housed in a specific pathogen-free facility in microisolator cages, given autoclaved food and water. All experiments were carried out according to the Federation of European Laboratory Animal Science Association guidelines and all protocols were approved by the Institutional Animal Care and Use Committees of Guangxi Medical University, Nanning, Guangxi, China.

Construction of $\alpha-1,3-G T$ genes and lentiviral transduction of MDA-MB-231 cells. Lentiviral containing $\alpha-1,3-\mathrm{GT}$ genes were constructed as previously described. The cDNAs expressing $\alpha-1,3-G T$ was cloned into a lentiviral vector pLVX- Puro. The reconstructed lentiviral plasmid or empty lentiviral plasmid vector were co-transfected into the 293T cells to produce virus stock. MDA-MB-231 cells were infected by lentiviral stably expressing $\alpha-1,3-$ GT-His and then cultured in complete DMEM media and $0.35 \mu \mathrm{g} / \mathrm{ml}$ puromycin. Cells were selected with puromycin and were named MDA-MB-231 Gal+ cells. Similarly, the control cell were named MDA-MB-231 ${ }^{\text {Gal- }}$ cells.

$R T-P C R$. RT-PCR was performed as previously described (24). mRNA was obtained from MDA-MB-231 ${ }^{\mathrm{Gal}+}$ cells, MDA-MB-231 ${ }^{\text {Gal- }}$ cells by use of the RNeasy kit (Qiagen). cDNA was synthesized from total RNA. Sequences of primers were for $\alpha-1,3-\mathrm{GT}$ (forward, TGCTTGTCTCAACTGTAATG; reverse, TCTTCTTCTTCGTGGTAACT), $\beta$-actin (forward, ACCACACCTTCTACAATGA; reverse, ATAGCACAGCC TGGATAG) designed by primer premier 5.0. RT-PCR was carried out in a Applied Biosystems 7300 real-time PCR system. Results were analysed by use of Light Cycler Software version 3 .

Western blotting. MDA-MB-231 $1^{\mathrm{Gal}-}$, MDA-MB-231 ${ }^{\mathrm{Gal}+}$ tumor cells were washed at $4^{\circ} \mathrm{C}$ and lysed in RIPA buffer on ice. Then, cell lysates were centrifuged at $13,000 \mathrm{~g}$ at $4^{\circ} \mathrm{C}$ for $20 \mathrm{~min}$. Total protein concentration in the cell lysate was measured by BCA Protein Quantification kit (Beyotime Biotechnology). Cell lysates were separated by SDS-PAGE and transferred onto a nitrocellulose membrane. The nitrocellulose membrane was incubated with primary His antibody at $4^{\circ} \mathrm{C}$ overnight. After washing the nitrocellulose membrane with TBS-T three times for $10 \mathrm{~min}$ each at room temperature, the nitrocellulose membrane was incubated with horseradish peroxidase (HRP)conjugated anti-IgG Abs (ZSGB-Bio, Beijing, China). Protein band intensities were quantified by use of the diaminobenzidine (DAB) kit (SolarBio, Beijing, China). $\beta$-actin was used as internal control.

Immune and tumor models. Human PBMCs and serum were obtained from fresh peripheral blood of healthy volunteers, with signed informed consent for use of blood in accordance with the Declaration of Helsinki. PBMCs were isolated by Ficoll Hypaque density-gradient centrifugation. PBMCs were suspended at a density of $1 \times 10^{8}$ cells $/ \mathrm{ml}$ by RPMI-1640. PBMCs suspension $(100 \mu \mathrm{l})$ and $100 \mu \mathrm{l}$ serum were injected into NOD-SCID mice. NOD-SCID mice with reconstituted intact human immune system were named Hu-NOD-SCID mice.

To study protective effect of these vaccines, the Hu-NOD-SCID mice were inoculated with $2 \times 10^{6}$ irradiated MDA-MB-231 ${ }^{\mathrm{Gal}+}$, MDA-MB-231 ${ }^{\mathrm{Gal}-}$ tumor cell vaccines, or phosphate-buffered saline (PBS) intraperitoneally on days 0 , 7, 14 and 21. After the completion of immunization, Hu-NODSCID mice were implanted with $1 \times 10^{6}$ live MDA-MB-231 tumor cells into the right side. Animal experiments were approved by the Institutional Animal Care and Use Committees of Guangxi Medical University, Nanning, Guangxi, China.

To study the antitumor effect of these vaccines on tumor-bearing Hu-NOD-SCID mice, the tumor-bearing Hu-NOD-SCID mice were injected $1 \times 10^{6}$ irradiated MDA-MB-231 ${ }^{\mathrm{Gal}+}$, MDA-MB-231 ${ }^{\mathrm{Gal}-}$ tumor cell vaccines or PBS on days 7, 14 and 21 after $\mathrm{Hu}-\mathrm{NOD}-\mathrm{SCID}$ mice were implanted with $1 \times 10^{6}$ live MDA-MB-231 tumor cells into the right side on day 0 .

Tumor volume was measured every 5 days, according to the formula: width ${ }^{2} \mathrm{x}$ length $\mathrm{x} 0.52$. Mice were monitored every day until they died, the date of death were recorded.

Flow cytometry. A total of $5 \times 10^{5}$ MDA-MB-231 $1^{\mathrm{Gal}+}$, MDA-MB$231^{\text {Gal- }}$ cells were incubated with Isolectin Griffonia simplicifolia- $\mathrm{IB}_{4}$ (Invitrogen, CA, USA) at $4^{\circ} \mathrm{C}$ for $1 \mathrm{~h}$. The $\alpha$-Gal reacted with Isolectin GS-IB4 was detected by flow cytometry (Beckman Coulter Epics XL-MCL, MA, USA) (25).

To determine whether the immune cells change in the tumor of mice immunized by tumor cell vaccines. The tumor cell suspensions were obtained from tumor-bearing mice. Tumor cell suspensions were incubated with FITC-conjugated anti-CD8 antibody and PE-conjugated anti-CD3 antibody at $4^{\circ} \mathrm{C}$ for $30 \mathrm{~min}$ for extracellular staining. The fluorescently stained cells were detected by flow cytometry (Beckman Coulter Epics XL-MCL), and the data were analyzed using FlowJo Software 7.6.2 (OR, USA).

ELISA. The levels of INF- $\gamma$, IL-12, IL-10, TGF- $\beta$ in serum of mice were quantified by ELISA according to the 
A

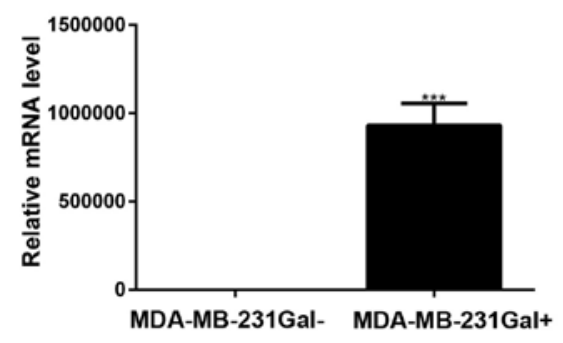

B

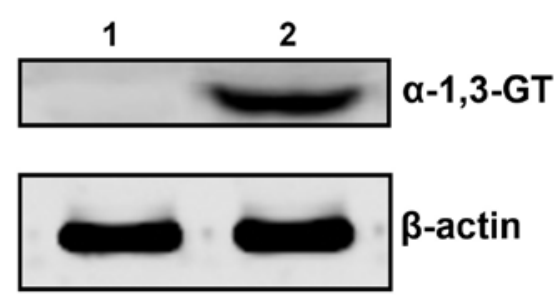

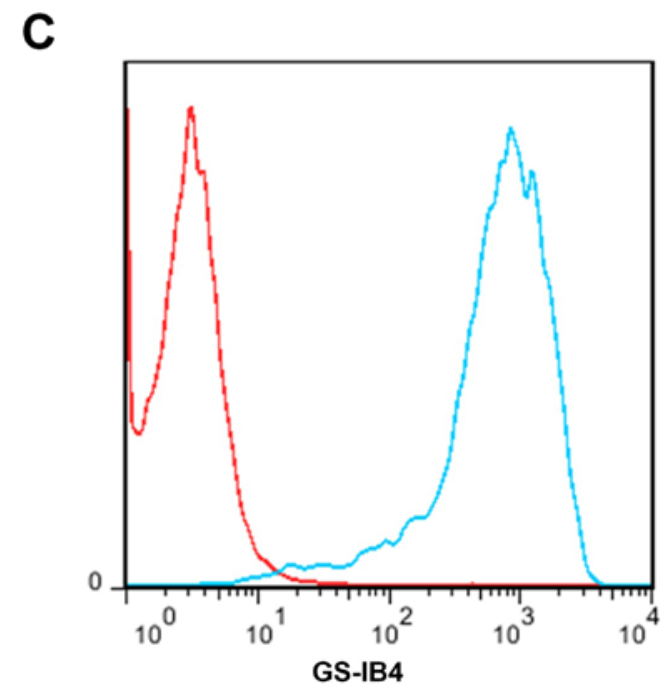

Figure 1. Tumor cells transfected by lentiviral expressed active $\alpha-1,3-\mathrm{GT}$ in vitro. MBA-MB-231 cells were transfected with $\alpha-1,3-\mathrm{GT}$ genetically modified lentiviral. (A) Expression of $\alpha-1,3-$ GT RNA in MDA-MB-231 ${ }^{\text {Gal- }}$ and MDA-MB-231 ${ }^{\text {Gal+ }}$ cells were measured by real-time PCR. (B) Western blot analysis was used to detect the expression of $\alpha-1,3-$ GT in MDA-MB-231 Gal- (line 1) cells, MDA-MB-231 Gal+ (line 2) cells. $\beta$-actin was used as internal control. (C) Expression of $\alpha-$ Gal in the MDA-MB-231 ${ }^{\text {Gal- }}$ (red line), and MDA-MB-231 ${ }^{\text {Gal+ }}$ (blue line) cells was measured by flow cytometry.

manufacturer's instructions. Optical densities were texted by use of a microplate reader at 450-nm wavelength. The data are presented as the means of triplicate wells.

Immunohistochemistry. Cell proliferation and apoptosis in tumor xenografts of mice were evaluated by immunohistochemistry. Tumor tissues were cut to $0.4-\mathrm{mm}$ sections, deparaffinized with xylene and graded alcohols. Endogenous peroxidase inactivation and antigen retrieval of tumor tissues were performed by standard procedure. Proliferation was evaluated by Ki67 immunostaining. TdT-mediated dUTP-biotin nick end labeling (TUNEL) was used to detect apoptotic cells in FFPE cell blocks.

Statistical analysis. Data were analysed by using SPSS 17.0. Data are expressed as mean \pm SD. The significance of the results of experiments was analysed by one-way ANOVA. Survival curves were analyzed by Kaplan-Meier method and the log-rank test. Three replicates were done for each experiment. ${ }^{*} \mathrm{P}<0.05,{ }^{* *} \mathrm{P}<0.01,{ }^{* * *} \mathrm{P}<0.001,{ }^{* * * *} \mathrm{P}<0.0001$ compared with PBS control (CON).

\section{Results}

MDA-MB-231 Gal+ tumor cells can express $\alpha-1,3-G T$ in vitro. MDA-MB-231 ${ }^{\mathrm{Gal}+}$ tumor cells were transfected with the $\alpha-1$,
3-GT expression lentiviral or empty lentiviral as described in Materials and methods. Total RNA and protein samples were obtained from MDA-MB-231 ${ }^{\text {Gal+ }}$ and MDA-MB-231 $1^{\text {Gal- }}$ tumor cells, and then analyzed via RT-PCR and western blotting using antibody. As shown in Fig. $1 \mathrm{~A}$ and B, the $\alpha-1,3-\mathrm{GT}$ RNA and $\alpha-1,3-$ GT were detected in the MDA-MB-231 ${ }^{\mathrm{Gal}+}$ cells, but not in MDA-MB-231 $1^{\text {Gal- }}$ cells.

To assess $\alpha$-Gal generated by $\alpha-1,3-G T$, MDA-MB-231 $1^{\mathrm{Gal}+}$ cells were incubated with Isolectin $\mathrm{GS}-\mathrm{IB}_{4}$ and then detected by flow cytometry (25). As shown in Fig. 1C, the results showed higher levels of $\alpha$-Gal in the MDA-MB-231 ${ }^{\mathrm{Gal}+}$ tumor cells than in the MDA-MB-231 ${ }^{\text {Gal- }}$ cells. These results demonstrated that the MDA-MB-231 ${ }^{\mathrm{Gal}+}$ cells expressed active $\alpha-1,3-\mathrm{GT}$ and produced $\alpha-\mathrm{Gal}$ epitope in vitro.

MDA-MB-231 ${ }^{\text {Gal }}$ cell vaccines inhibit tumor growth and tumorigenesis in immunized mice. In order to study whether the irradiated MDA-MB-231 ${ }^{\mathrm{Gal}+}$ cell vaccines induced protective antitumor immunity, we evaluated the formation and growth of tumors in immunized mice. Hu-NOD-SCID mice were immunized with irradiated tumor cell vaccines and challenged with live MDA-MB-231 tumor cells as previously described. As shown in Fig. 2, tumorigenesis rates in mice immunized with MDA-MB-231 ${ }^{\mathrm{Gal}+}$ cell vaccines were lower than in mice immunized with MDA-MB-231 $1^{\text {Gal- }}$ cells or PBS. Tumor growth curves showed that the tumor growth in mice 
A

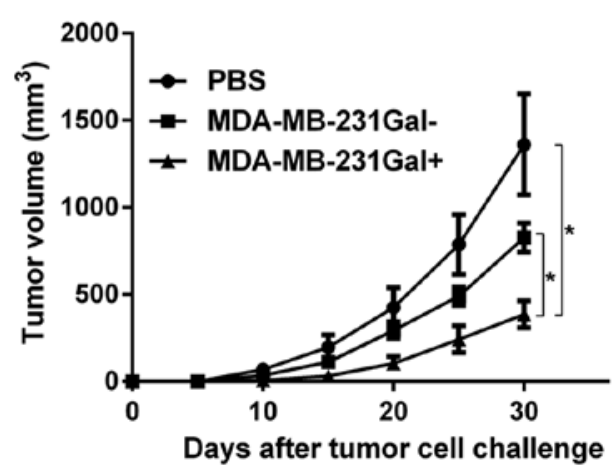

C

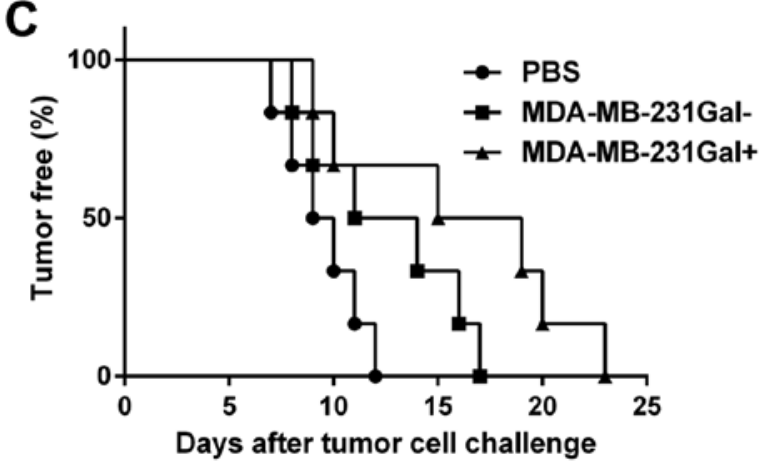

B

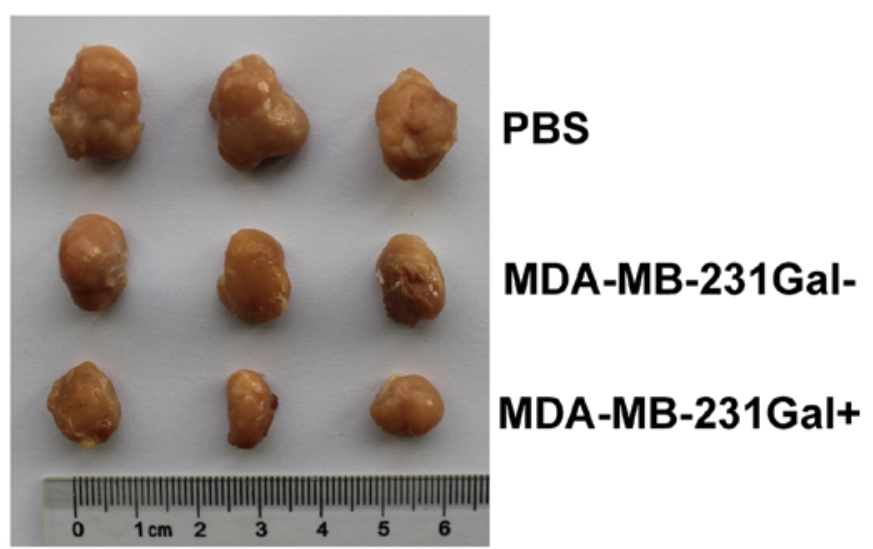

Figure 2. Induction of protective antitumor immunity. Hu-NOD-SCID mice were immunized with MDA-MB-231 ${ }^{\text {Galt }}$ cells, MDA-MB-231 ${ }^{\text {Gal- }}$ cells or PBS on days $0,7,14$ and 21, and then challenged with live MDA-MB-231 cells on day 28. (A) Tumor volume of the mice immunized with MDA-MB-231 ${ }^{\text {Galt }}$ cells, MDA-MB-231 Gal- cells or PBS. (B) Representative xenograft tumors of mice in each group. (C) Tumor-free survival of the mice immunized with MDAMB-231 $1^{\text {Galt }}$ cells, MDA-MB-231 Gal- $^{\text {cells }}$ or PBS.

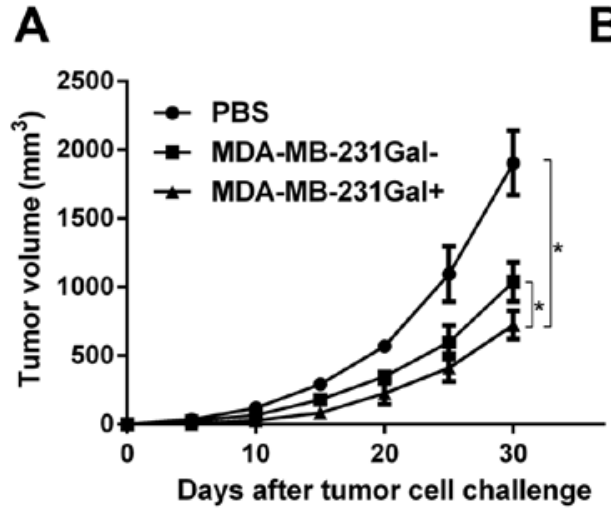

C

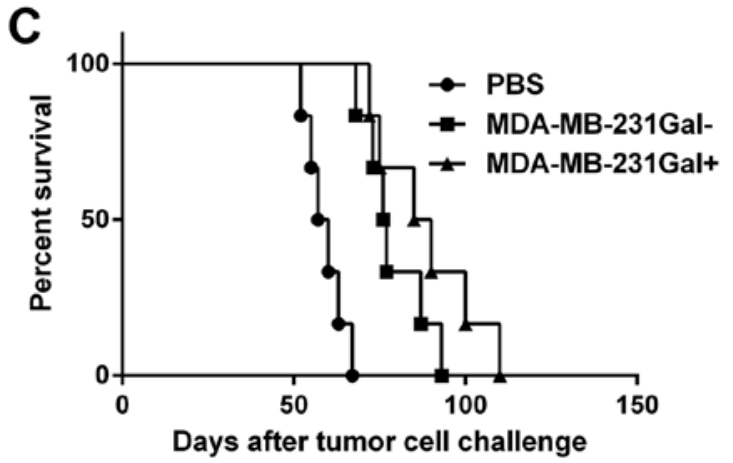

Figure 3. Induction of therapeutic antitumor immunity. Hu-NOD-SCID mice were treated with MDA-MB-231 ${ }^{\text {Gal+ }}$ cells, MDA-MB-231 ${ }^{\text {Gal- }}$ cells or PBS on days 7, 14 and 21 after challenged by $1 \times 10^{6}$ live MDA-MB-231 cells on day 0 . (A) The tumor volume of mice immunized with MDA-MB-231 ${ }^{\text {Gal+ }}$ cells or MDA-MB-231 ${ }^{\text {Gal- }}$ cells or PBS. (B) Representative xenograft tumors of Hu-NOD-SCID mice in each group. (C) Survival curves of mice immunized with MDA-MB-231 ${ }^{\text {Gal+ }}$ cells or MDA-MB-231 ${ }^{\text {Gal- }}$ cells or PBS. 


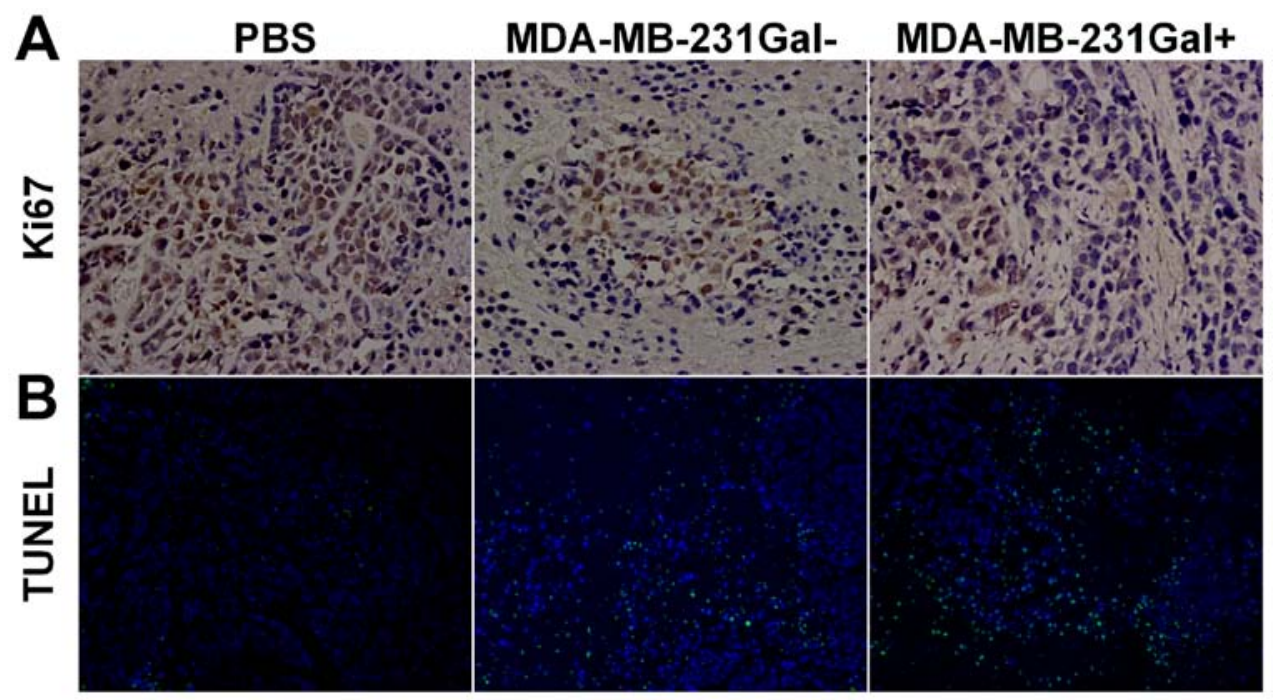

C

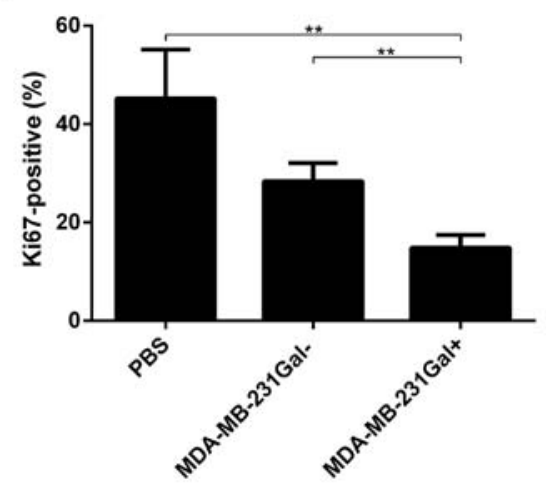

D

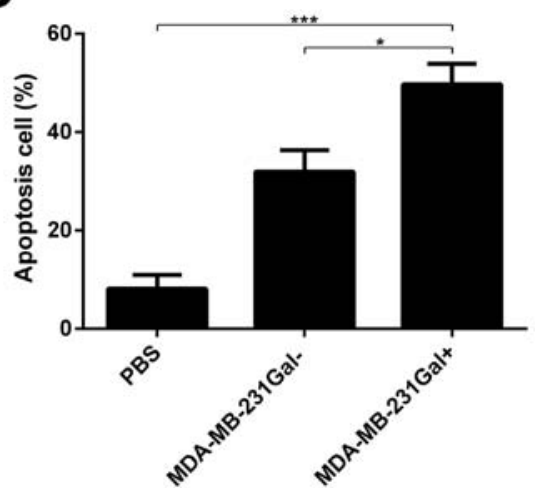

Figure 4. Apoptosis and proliferation in tumor xenografts. (A) Proliferation in MDA-MB-231 tumor tissue of mice. Paraffin-embedded tumor sections were stained for Ki67. Fluorescence (Ki67) was evaluated and representative microscope images are presented (x400). (B) Apoptosis in MDA-MB-231 tumor tissue of mice. Paraffin-embedded tumor sections were stained for TUNEL. Fluorescence (TUNEL) was evaluated and representative microscope images are presented (x200). (C and D) Statistics of TUNEL, Ki67 positive staining in tumor sections. Data are the mean and $\mathrm{SEM}(\mathrm{n}=3)$. ${ }^{*} \mathrm{P}<0.05,{ }^{* *} \mathrm{P}<0.01,{ }^{* * * *} \mathrm{P}<0.001$, ${ }^{* * * *} \mathrm{P}<0.0001$ compared with PBS control (CON).

immunized with MDA-MB-231 ${ }^{\mathrm{Gal}+}$ cell vaccines was slower than other groups.

MDA-MB-231 ${ }^{\text {Gal+ }}$ cell vaccines inhibit tumor growth in mammary tumor-bearing mice. The antitumor efficacy of MDA-MB-231 ${ }^{\text {Gal+ }}$ cell vaccines was evaluated in mammary tumor models. Tumor-bearing mice were injected with the tumor cell vaccines three times. As shown in Fig. 3, tumor growth in the MDA-MB-231 ${ }^{\mathrm{Gal}+}$ tumor cell vaccines treated group was significantly slower and the lifespan in the MDA-MB-231 ${ }^{\mathrm{Gal}+}$ tumor cell vaccines treated group was markedly prolonged compared with the other control groups. These data demonstrated that MDA-MB-231 ${ }^{\mathrm{Gal}+}$ tumor cell vaccines were more effective than the control groups in eliciting antitumor effect in tumor-bearing mice.

MDA-MB-231 Gal+ tumor cell vaccines increase apoptosis and inhibit proliferation in tumor xenografts of mice. To measure apoptotic cells in tumor xenografts of mice, we performed TdT-mediated dUTP-biotin nick end labeling (TUNEL). As shown in Fig. 4, MDA-MB-231 ${ }^{\mathrm{Gal}+}$ tumor cell vaccines significantly increased the number of apoptotic cells compared with the other control groups. To evaluate the effect of MDA-MB-231 ${ }^{\text {Gal+ }}$ cell vaccines on proliferation of tumor, it was assessed by counting Ki67-positive tumor cells. MDA-MB-231 ${ }^{\mathrm{Gal}+}$ tumor cell vaccines significantly inhibited proliferation of tumor compared with the other control groups. In summary, these data indicated that MDA-MB-231 ${ }^{\mathrm{Gal}+}$ tumor cell vaccines significantly inhibited growth of breast cancer.

The levels of cytokine secretion in the serum of mice treated with tumor cell vaccines. Cytokine secretion was analyzed to determine immunity activation. Mice were treated at indicated time and dose, expression of IL-12p70, INF- $\gamma$, IL-10, TGF- $\beta$ in the serum of mice treated with tumor cell vaccines was measured. As shown in Fig. 5, the levels of IL-12p70, INF- $\gamma$ in the serum of mice treated with MDA-MB-231 ${ }^{\text {Gal+ }}$ tumor cell vaccines were significantly higher than mice treated with MDA-MB-231 ${ }^{\text {Gal- }}$ tumor cells or PBS, whereas the levels of IL-10, TGF- $\beta$ were contrary.

MDA-MB-231 $1^{\text {Gal+ }}$ tumor cell vaccines enhance $C D 8^{+} T$ cells recruitment in the tumor microenvironment. To determine $\mathrm{CD}^{+} \mathrm{T}$ cells in the solid tumors, we performed flow cytometry to identify $\mathrm{CD}^{+} \mathrm{T}$ cells in the solid tumor cell suspension. As shown in Fig. 6, MDA-MB-231 ${ }^{\text {Gal+ }}$ cell vaccines significantly 
A

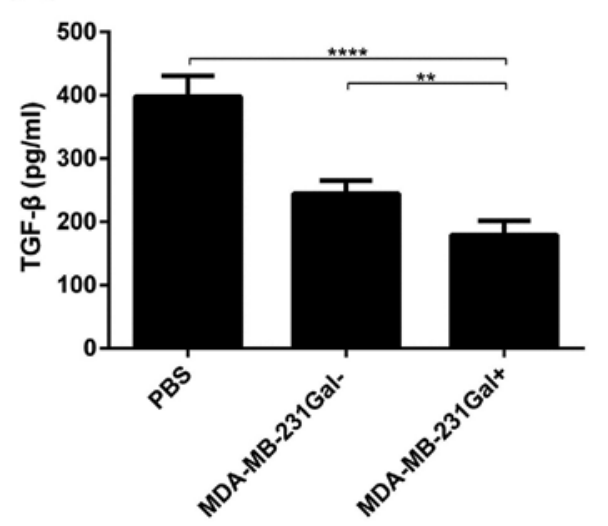

C

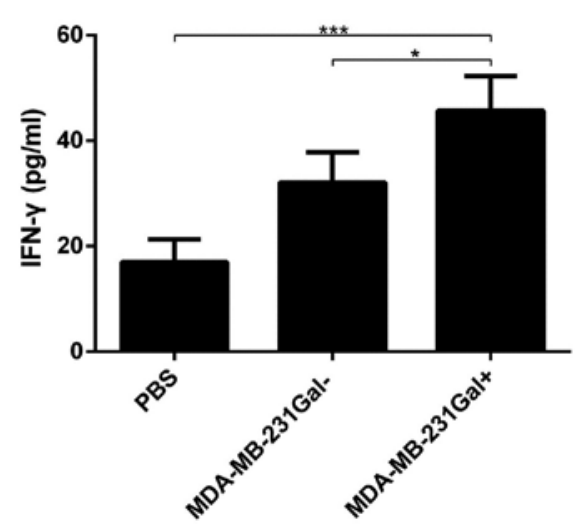

B

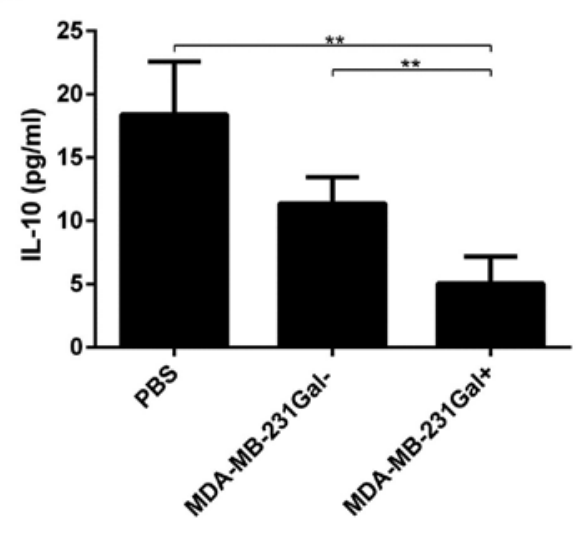

D

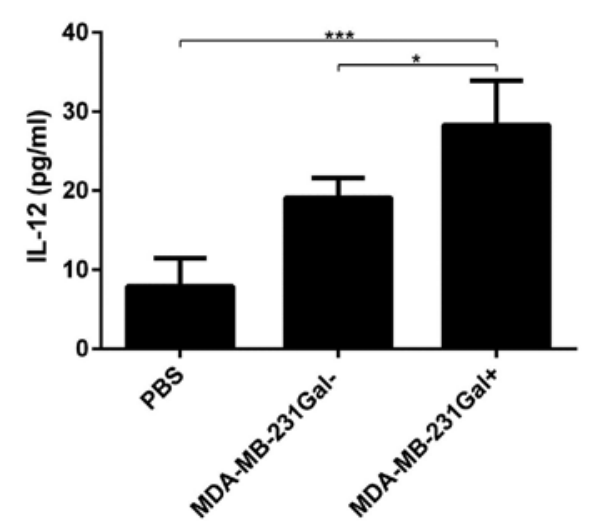

Figure 5. The levels of cytokine in the serum of mice. Hu-NOD-SCID mice were treated with MDA-MB-231 $1^{\text {Galt }}$ cells or MDA-MB-231 $1^{\text {Gal- }}$ cells or PBS. ELISA was performed to test the (A) TGF- $\beta$, (B) IL-10, (C) INF- $\gamma$ and (D) IL-12p70 production in serum of mice. Data are the mean and SEM (n=3). ${ }^{*} \mathrm{P}<0.05,{ }^{* *} \mathrm{P}<0.01$, ${ }^{* * * *} \mathrm{P}<0.001,{ }^{* * * *} \mathrm{P}<0.0001$ compared with PBS control.

increased the percentage of $\mathrm{CD}^{+} \mathrm{T}$ cells in the solid tumor cell suspension. These results showed that MDA-MB-231 ${ }^{\mathrm{Gal}+}$ tumor cell vaccines promoted the recruitment of antitumor immune effective cells in the tumor microenvironment.

\section{Discussion}

Many studies have indicated that tumor cell vaccines have higher efficiency when treated in combination with immunologic adjuvant, chemotherapy and radiotherapy, cytokines $(5,6)$. In addition, genetically modified tumor cell vaccines can also induce highly effective antitumor effect. Different genetically modified tumor cell vaccines have been developed, most of which were transfected with genes encoding proteins such as IL-12, IL-4, IL-7, IL-2, IL-6/sIL-6R, GM-CSF, TNF, IFN- $\gamma$, HLA molecules (HLA-B7), co-stimulatory molecules (B-7,1) $(3,26,27)$. With advances in genetically modified technology, tumor cell vaccines will be introduced into cancer immunotherapy in clinical practice.

In our studies, MDA-MB-231 ${ }^{\mathrm{Gal}+}$ cells were transfected with lentiviral recombined $\alpha-1,3-\mathrm{GT}$ genes and expressed bioactive $\alpha-1,3-\mathrm{GT}$ in vitro. In this assay, we used live MDA-MB-231 tumor cells to generate tumor models to evaluate the antitumor effects of MDA-MB-231 $1^{\mathrm{Gal}+}$ cell vaccines. Our data showed that MDA-MB-231 ${ }^{\text {Gal+ }}$ cell vaccines inhibited tumor growth and tumorigenesis and proliferation in tumor xenografts of mice. In addition, MDA-MB-231 ${ }^{\mathrm{Gal}+}$ cell vaccines could promote the levels of cytokine secretion and the recruitment of antitumor immune effective cells and apoptosis in tumor xenografts of mice. Our result implied that MDA-MB-231 ${ }^{\mathrm{Gal}+}$ tumor cell vaccines could produce strong protective and antitumor immune effect. The result showed that genetically modified MDA-MB-231 ${ }^{\mathrm{Gal}+}$ tumor cell vaccines represent promising strategies for highly effective antitumor therapies.

An efficient antitumor immune response induced by tumor antigen was not expressed, or expressed weakly on normal cells. The ideal tumor antigen should be expressed in all cancer and immunogenic cells $(3,28)$. Unfortunately, some of normal cells may also express tumor antigens. So tumor cells are not immunogenic enough to elicit immune response (28). However, studies have shown that the $\alpha$-Gal epitope increased the immunogenicity of viral vaccines, including the human immunodeficiency virus (HIV) vaccine and flu vaccine (29). The $\alpha$-Gal epitope expressing on vaccines specifically binds to anti-Gal antibody (30). The anti-Gal antibody also binds with the antigen presenting cells (APCs), which can promote the highly effective uptake of $\alpha$-Gal epitope on the vaccine by APCs (31-33). In addition, then antigen-specific $\mathrm{CD}^{+}$ $\mathrm{T}$ cells are activated by MHC class I and class II molecules expressed on APCs. The antitumor immune response is mainly 
A

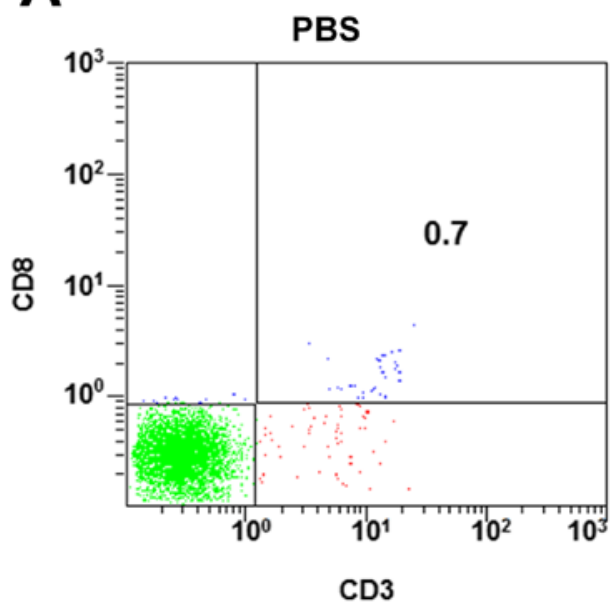

MDA-MB-231Gal+

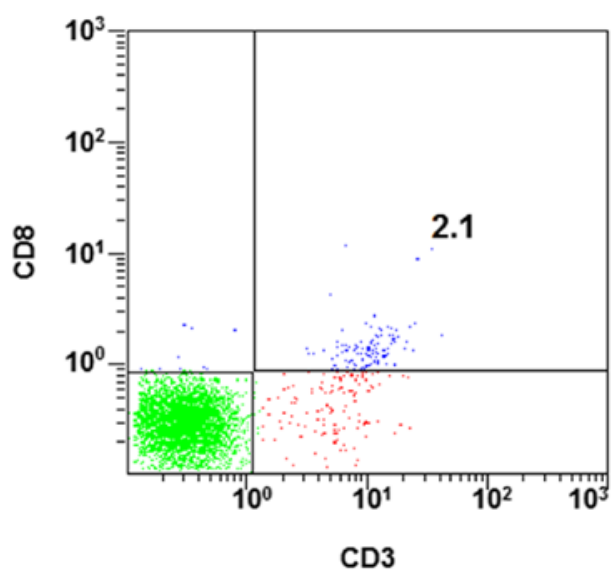

MDA-MB-231Gal-

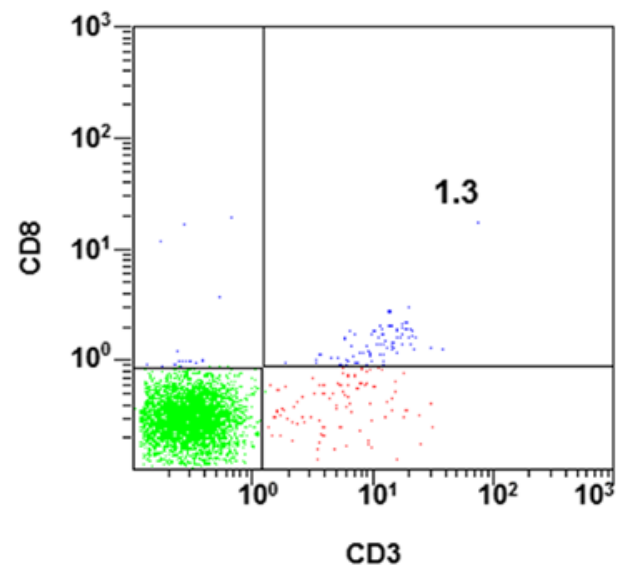

B

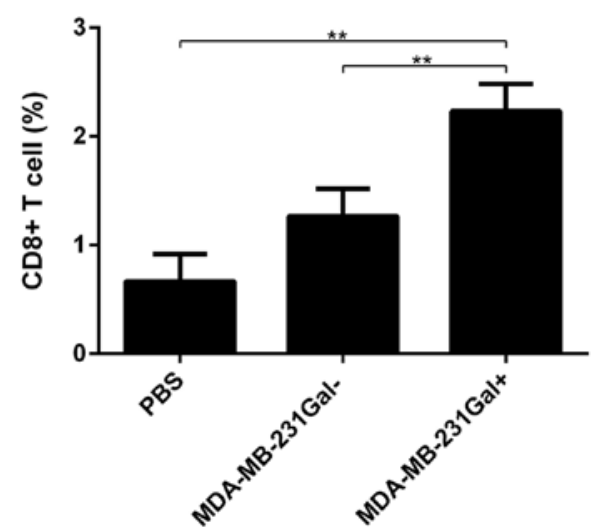

Figure 6. The levels of $\mathrm{CD}^{+} \mathrm{T}$ cells in immunized mice were analysed by flow cytometry. (A) Tumor cell suspensions were incubated with anti-human CD8 antibodies (FITC conjuncted) and anti-human CD3 antibodies (PE conjuncted) to identify CD8 ${ }^{+} \mathrm{T}$ lymphocytes. (B) Statistics of CD8+ T lymphocytes in each group. Data are the mean and SEM $(\mathrm{n}=3) .{ }^{*} \mathrm{P}<0.05,{ }^{* *} \mathrm{P}<0.01,{ }^{* * *} \mathrm{P}<0.001,{ }^{* * * *} \mathrm{P}<0.0001$ compared with PBS. control.

mediated by antigen-specific $\mathrm{CD}^{+} \mathrm{T}$ cells (34). In our studies, MDA-MB-231 ${ }^{\text {Gal+ }}$ cell vaccines achieve high antitumor effects, which may owe to $\alpha$-Gal epitope. However, further studies are required to determine the molecular mechanisms.

Studies have shown that tumor cells escape from immune effectors attack via complementary immunosuppressive mechanisms which make immunologic effector cell anergy. Tumor cells can improve secretion of immunosuppressive molecules and cytokines such as IL-10 and TGF- $\beta$ (35), which inhibit antitumor immunity responses and enhance Treg cell functions. TGF- $\beta$ could also inhibit dendritic cell differentiation $(36,37)$ and $\mathrm{NK}$ cell immunologic functions (38). As shown in Fig. $5 \mathrm{~A}$ and $\mathrm{B}$, an decrease of TGF- $\beta$, IL-10 were observed in MDA-MB-231 ${ }^{\mathrm{Gal}+}$ cell vaccinated mice. Therefore, MDA-MB-231 ${ }^{\mathrm{Gal}+}$ cell vaccines can reduce immunosuppressive cytokine production.

As shown in Fig. 5C and D, increase of IFN- $\gamma$ and IL-12p70 were observed in MDA-MB-231 ${ }^{\mathrm{Gal}+}$ cell vaccinated mice. IFN- $\gamma$ is shown to have antitumorigenic immune effects (39) and activate $\mathrm{NK}$ cells, $\mathrm{CD}^{+} \mathrm{T}$ cells, and macrophages. IL-12 can stimulate NK cells and Th1 cells. Studies have shown that IL-12 plays a main role in antitumor immunity $(5,40)$ and protect prophylactically against live tumor cell challenge $(26,41)$. In a mouse model, IL-12 can increase infiltrating CD3 ${ }^{+}$ $\mathrm{T}$ cells (42). Therefore, this can account for MDA-MB-231 ${ }^{\mathrm{Gal}+}$ cell vaccines promoting antitumor immunity.

Taken together, immunotherapy has been the focus of tumor therapy study (43). Our studies are the first report showing that MDA-MB-231 ${ }^{\mathrm{Gal}+}$ cell vaccines induced powerful protective and antitumor effect. Notably, MDA-MB-231 ${ }^{\text {Gal+ }}$ cell vaccines directly enhanced the recruitment of effector $\mathrm{T}$ cells and promoted the levels of cytokine secretion and cell apoptosis in tumor-bearing mice. These results implicate genetically modified tumor cells as vaccines can be exploited as a powerful therapeutic strategy for cancer, but more studies are necessary before performing clinical trials.

\section{Acknowledgements}

This study was supported, in part, by grants from Programs for Changjiang Scholars and Innovative Research Team in University (no. IRT_15R13); National Natural Scientific Foundation of China (nos. 81430055 and 81372452); International Cooperation Project of the Ministry of Science 
and Technology of China (no. 2015DFA31320); Project for Innovative Research Team in Guangxi Natural Science Foundation (2015GXNSFFA139001); Project of Science and Technology of Guangxi (nos. 14125008-2-12 and 15990052-10).

\section{References}

1. Euhus DM, Gupta RK and Morton DL: Induction of antibodies to a tumor-associated antigen by immunization with a whole melanoma cell vaccine. Cancer Immunol Immunother 29: 247-254, 1989.

2. Chiang CL, Coukos G and Kandalaft LE: Whole tumor antigen vaccines: Where are we? Vaccines (Basel) 3: 344-372, 2015.

3. Nawrocki S and Mackiewicz A: Genetically modified tumour vaccines - where we are today. Cancer Treat Rev 25: 29-46, 1999.

4. Ward S, Casey D, Labarthe MC, Whelan M, Dalgleish A, Pandha $\mathrm{H}$ and Todryk S: Immunotherapeutic potential of whole tumour cells. Cancer Immunol Immunother 51: 351-357, 2002.

5. Mach N and Dranoff G: Cytokine-secreting tumor cell vaccines. Curr Opin Immunol 12: 571-575, 2000.

6. Copier J and Dalgleish A: Overview of tumor cell-based vaccines. Int Rev Immunol 25: 297-319, 2006.

7. Chiang CL, Benencia F and Coukos G: Whole tumor antigen vaccines. Semin Immunol 22: 132-143, 2010.

8. Drake CG, Lipson EJ and Brahmer JR: Breathing new life into immunotherapy: Review of melanoma, lung and kidney cancer. Nat Rev Clin Oncol 11: 24-37, 2014.

9. Hsueh EC, Essner R, Foshag LJ, Ollila DW, Gammon G, O'Day SJ, Boasberg PD, Stern SL, Ye X and Morton DL: Prolonged survival after complete resection of disseminated melanoma and active immunotherapy with a therapeutic cancer vaccine. J Clin Oncol 20: 4549-4554, 2002.

10. Copier J and Dalgleish A: Whole-cell vaccines: A failure or a success waiting to happen? Curr Opin Mol Ther 12: 14-20, 2010.

11. Kraman M, Bambrough PJ, Arnold JN, Roberts EW, Magiera L, Jones JO, Gopinathan A, Tuveson DA and Fearon DT: Suppression of antitumor immunity by stromal cells expressing fibroblast activation protein-alpha. Science 330: 827-830, 2010.

12. Speiser DE, Baumgaertner P, Barbey C, Rubio-Godoy V, Moulin A, Corthesy P, Devevre E, Dietrich PY, Rimoldi D, Liénard D, et al: A novel approach to characterize clonality and differentiation of human melanoma-specific $T$ cell responses: Spontaneous priming and efficient boosting by vaccination. J Immunol 177: 1338-1348, 2006.

13. Galili U: Discovery of the natural anti-Gal antibody and its past and future relevance to medicine. Xenotransplantation 20: 138-147, 2013.

14. Park HM, Kim YW, Kim KJ, Kim YJ, Yang YH, Jin JM, Kim YH, Kim BG, Shim H and Kim YG: Comparative N-linked glycan analysis of wild-type and $\alpha 1,3$-galactosyltransferase gene knock-out pig fibroblasts using mass spectrometry approaches. Mol Cells 38: 65-74, 2015.

15. Galili U: Significance of the evolutionary $\alpha 1,3$-galactosyltransferase (GGTA1) gene inactivation in preventing extinction of apes and old world monkeys. J Mol Evol 80: 1-9, 2015.

16. Qiu Y, Yun MM, Dong X, Xu M, Zhao R, Han X, Zhou E, Yun F, Su W, Liu C, et al: Combination of cytokine-induced killer and dendritic cells pulsed with antigenic $\alpha-1,3$-galactosyl epitope-enhanced lymphoma cell membrane for effective B-cell lymphoma immunotherapy. Cytotherapy 18: 91-98, 2016.

17. Sato M, Kagoshima A, Saitoh I, Inada E, Miyoshi K, Ohtsuka M, Nakamura S, Sakurai T and Watanabe S: Generation of alpha1,3-galactosyltransferase-deficient porcine embryonic fibroblasts by CRISPR/Cas9-mediated knock-in of a small mutated sequence and a targeted toxin-based selection system. Reprod Domest Anim 50: 872-880, 2015.

18. Shimatsu Y, Yamada K, Horii W, Hirakata A, Sakamoto Y, Waki S, Sano J, Saitoh T, Sahara H, Shimizu A, et al: Production of cloned NIBS (Nippon Institute for Biological Science) and $\alpha$-1, 3-galactosyltransferase knockout MGH miniature pigs by somatic cell nuclear transfer using the NIBS breed as surrogates. Xenotransplantation 20: 157-164, 2013.

19. Park CS, Oh SS, Kim YE, Choi SY, Lim HG, Ahn H and Kim YJ: Anti-alpha-Gal antibody response following xenogeneic heart valve implantation in adults. J Heart Valve Dis 22: 222-229, 2013.
20. Wilczek P, Lesiak A, Niemiec-Cyganek A, Kubin B, Slomski R, Nozynski J,Wilczek G,Mzyk A and GramatykaM: Biomechanical properties of hybrid heart valve prosthesis utilizing the pigs that do not express the galactose- $\alpha-1,3$-galactose $(\alpha-\mathrm{Gal})$ antigen derived tissue and tissue engineering technique. J Mater Sci Mater Med 26: 5329, 2015.

21. Galili U: Anti-Gal: An abundant human natural antibody of multiple pathogeneses and clinical benefits. Immunology 140: 1-11, 2013.

22. Saethre M, Schneider MK, Lambris JD, Magotti P, Haraldsen G, Seebach JD and Mollnes TE: Cytokine secretion depends on Galalpha $(1,3) \mathrm{Gal}$ expression in a pig-to-human whole blood model. J Immunol 180: 6346-6353, 2008.

23. Wilhite T, Ezzelarab C, Hara H, Long C, Ayares D, Cooper DK and Ezzelarab M: The effect of Gal expression on pig cells on the human T-cell xenoresponse. Xenotransplantation 19: 56-63, 2012.

24. Zibara K, Awada Z, Dib L, El-Saghir J, Al-Ghadban S, Ibrik A, El-Zein N and El-Sabban M: Anti-angiogenesis therapy and gap junction inhibition reduce MDA-MB-231 breast cancer cell invasion and metastasis in vitro and in vivo. Sci Rep 5: 12598, 2015.

25. Lin SS, Parker W, Everett ML and Platt JL: Differential recognition by proteins of alpha-galactosyl residues on endothelial cell surfaces. Glycobiology 8: 433-443, 1998.

26. Miguel A, Herrero MJ, Sendra L, Botella R, Algás R, Sánchez M and Aliño SF: Comparative antitumor effect among GM-CSF, IL-12 and GM-CSF+IL-12 genetically modified tumor cell vaccines. Cancer Gene Ther 20: 576-581, 2013.

27. Golumbek PT, Azhari R, Jaffee EM, Levitsky HI, Lazenby A, Leong K and Pardoll DM: Controlled release, biodegradable cytokine depots: A new approach in cancer vaccine design. Cancer Res 53: 5841-5844, 1993.

28. Lu X, He J, Li X and Zhao Y: The relationship between malignant and tumor-associated cells provides a new strategy for targeted diagnosis and therapy. OncoImmunology 2: e26295, 2013

29. Abdel-Motal UM, Guay HM, Wigglesworth K, Welsh RM and Galili U: Immunogenicity of influenza virus vaccine is increased by anti-gal-mediated targeting to antigen-presenting cells. J Virol 81: 9131-9141, 2007.

30. Mangold A, Szerafin T, Hoetzenecker K, Hacker S, Lichtenauer M, Niederpold T, Nickl S, Dworschak M, Blumer R, Auer J, et al: Alpha-Gal specific IgG immune response after implantation of bioprostheses. Thorac Cardiovasc Surg 57: 191-195, 2009.

31. Galili U, Repik PM, Anaraki F, Mozdzanowska K, Washko G and Gerhard W: Enhancement of antigen presentation of influenza virus hemagglutinin by the natural human anti-Gal antibody. Vaccine 14: 321-328, 1996.

32. Abdel-Motal U, Wang S, Lu S, Wigglesworth K and Galili U: Increased immunogenicity of human immunodeficiency virus gp120 engineered to express Galalpha1-3Galbeta1-4GlcNAc-R epitopes. J Virol 80: 6943-6951, 2006.

33. Henion TR, Gerhard W, Anaraki F and Galili U: Synthesis of alpha-gal epitopes on influenza virus vaccines, by recombinant alpha 1,3galactosyltransferase, enables the formation of immune complexes with the natural anti-Gal antibody. Vaccine 15: 1174-1182, 1997.

34. Zinkernagel RM, Ehl S, Aichele P, Oehen S, Kündig T and Hengartner H: Antigen localisation regulates immune responses in a dose- and time-dependent fashion: A geographical view of immune reactivity. Immunol Rev 156: 199-209, 1997.

35. Thomas DA and Massagué J: TGF-beta directly targets cytotoxic $\mathrm{T}$ cell functions during tumor evasion of immune surveillance. Cancer Cell 8: 369-380, 2005.

36. Yamaguchi Y, Tsumura H, Miwa M and Inaba K: Contrasting effects of TGF-beta 1 and TNF-alpha on the development of dendritic cells from progenitors in mouse bone marrow. Stem Cells 15: 144-153, 1997.

37. Steinman RM, Hawiger D, Liu K, Bonifaz L, Bonnyay D, Mahnke K, Iyoda T, Ravetch J, Dhodapkar M, Inaba K, et al: Dendritic cell function in vivo during the steady state: A role in peripheral tolerance. Ann NY Acad Sci 987: 15-25, 2003.

38. Rook AH, Kehrl JH, Wakefield LM, Roberts AB, Sporn MB, Burlington DB, Lane HC and Fauci AS: Effects of transforming growth factor beta on the functions of natural killer cells: Depressed cytolytic activity and blunting of interferon responsiveness. J Immunol 136: 3916-3920, 1986.

39. Ikeda H, Old LJ and Schreiber RD: The roles of IFN gamma in protection against tumor development and cancer immunoediting. Cytokine Growth Factor Rev 13: 95-109, 2002. 
40. De Giovanni C, Nicoletti G, Landuzzi L, Astolfi A, Croci S, Comes A, Ferrini S, Meazza R, Iezzi M, Di Carlo E, et al: Immunoprevention of HER-2/neu transgenic mammary carcinoma through an interleukin 12-engineered allogeneic cell vaccine. Cancer Res 64: 4001-4009, 2004.

41. Sun Y, Jurgovsky K, Möller P, Alijagic S, Dorbic T, Georgieva J, Wittig B and Schadendorf D: Vaccination with IL-12 genemodified autologous melanoma cells: Preclinical results and a first clinical phase I study. Gene Ther 5: 481-490, 1998.
42. Fuji N, Fujiwara H, Ueda Y, Taniguchi F, Yoshimura T, Oka T and Yamagishi H: Augmentation of local antitumor immunity in the liver by tumor vaccine modified to secrete murine interleukin 12. Gene Ther 6: 1120-1127, 1999.

43. Lai C, Ye B, Hou X, Duan S, Wei X, Chen C, Zeng X, Liang W, Zhou S, Hu N, et al: Anti-tumor effect of folic acid-conjugated chitosan nanoparticles containing IL-33 gene in hepatocellular carcinoma. Cell Conmmun 1: 30-40, 2014. 